\title{
STRUCTURAL AND MAGNETIC PROPERTIES OF COCr RIBBONS
}

\author{
Ning ZHANG and J.C. LODDER \\ University of Twente, P.O. Box 217, 7500 AE Enschede, The Netherlands
}

Received 30 April 1990

\begin{abstract}
In this paper, heat-treated $\mathrm{CoCr}$ ribbons with 20 and 27 at\% $\mathrm{Cr}$ have been studied with the aim of understanding the segregation phenomenon which first emerged from sputtered $\mathrm{CoCr}$ films for perpendicular recording. Higher magnetization of a ribbon heated at 530 to $730^{\circ} \mathrm{C}$ has been found in comparison with the homogeneous CoCr composition. It favours the opinion that the segregation in a CoCr system is of energy equilibrium at certain temperatures. Based on our results, a re-interpretation of the $\mathrm{CoCr}$ phase diagram and a discussion on its relation to sputtered films with segregation are presented.
\end{abstract}

\section{Introduction}

$\mathrm{CoCr}$ sputtered medium for perpendicular recording was first mentioned by Iwasaki et al. in 1975 [1]. Although many other materials were proposed, $\mathrm{CoCr}$ is still the mostly used medium for the application in perpendicular recording. $U p$ to now more than $60 \%$ of all papers on recording media are concerned with $\mathrm{CoCr}$ [2]. During the last 5 years deposited (sputtered and evaporated) $\mathrm{CoCr}$ media have been improved in many aspects and very recently many good results have been reported on their practical use [3]. The basic magnetic properties such as magnetization, coercivity and anisotropy depend on the microstructural properties and chemical inhomogeneities like segregation of $\mathrm{Cr}$. The latter is mainly responsible for the deviation in saturation magnetization $\left(M_{\mathrm{s}}\right)$ from the Slater-Pauling [4] curve. In most studies the $M_{\mathrm{s}}$ of sputtered $\mathrm{CoCr}$ films is found to be larger than that of bulk alloys. In order to understand the sputtered films in more detail we started analysis of the properties of $\mathrm{CoCr}$ ribbons which were thought to be compositionally homogeneous and more or less amorphous due to the method used when they were being prepared.

\section{Binary phase diagrams of $\mathrm{CoCr}$}

There has been much literature published on the $\mathrm{CoCr}$ binary phase diagram [5-13]. Three representative kinds of phase diagram can be obtained from these references, and these are presented in fig. 1.

Hansen [14] and Moffatt [15] compiled the research of Elsea et al. [10] and Grigor'ev et al. [12], figs. 1(a) and (b), respectively, into handbooks as standard data. Meanwhile, fig. 1(c) shows the latest data obtained by Allibert et al. [13]. It is a pity that many uncertainties have been shown in the mentioned phase diagrams (see dashed lines of fig. 1) and that there are a lot of differences between them.

With respect to the application of $\mathrm{CoCr}$ as thin-film media for perpendicular recording there is more interest in the Co-rich part (10-40 at\% $\mathrm{Cr}$ ) of the phase diagram in the range from $\mathrm{RT}$ to $1000^{\circ} \mathrm{C}$. In such a range two phases, $\alpha$-hcp and $\beta$-fcc, are represented in every phase diagram. At RT the $\alpha$-phase is stable and ferromagnetic with a uniaxial anisotropy, if its $\mathrm{Cr}$ content being lower than 25 at\% [16]. Although the $\beta$-phase should be stable at high temperatures, a mixture of this with 

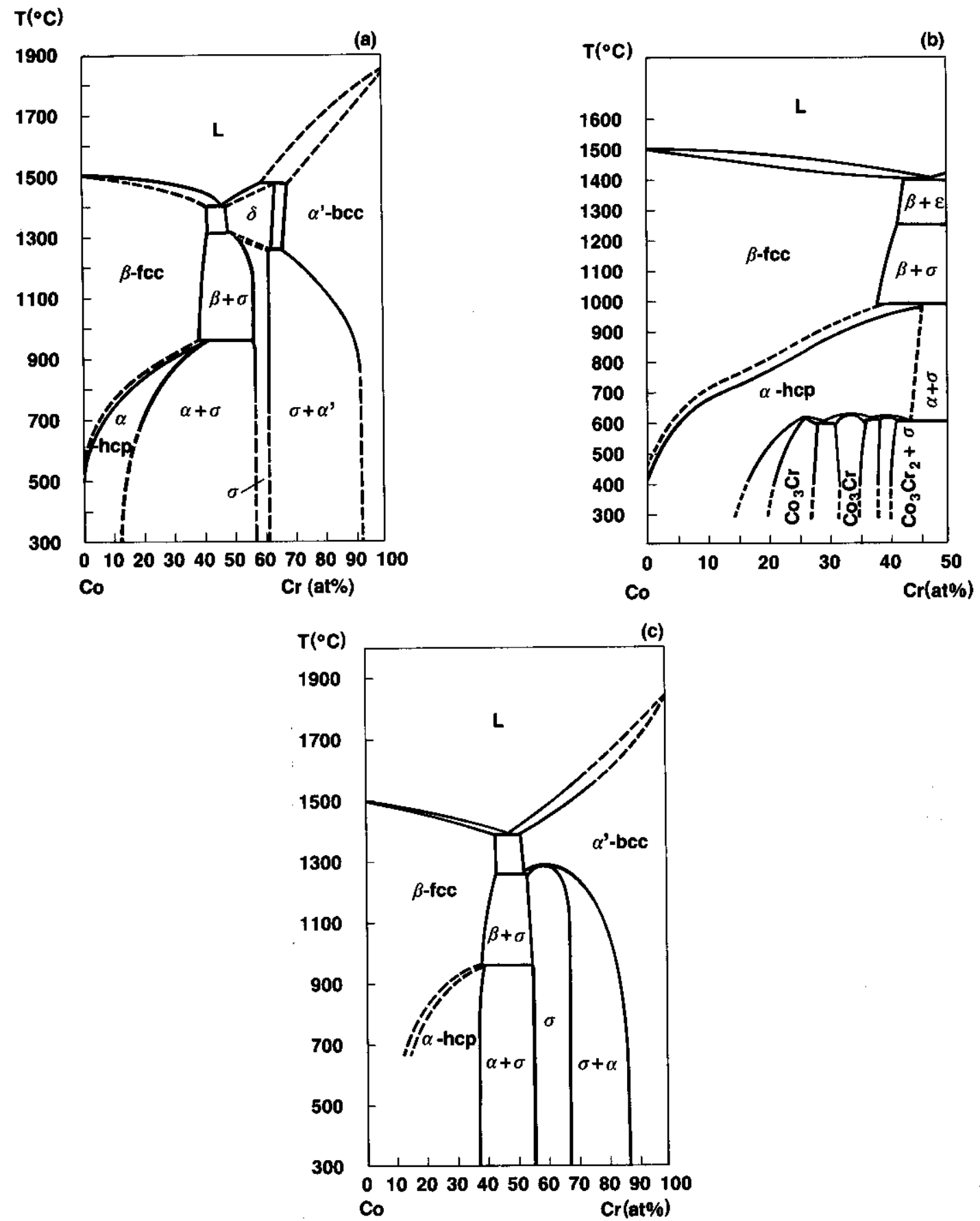

Fig. 1. Published phase diagrams of the binary CoCr system by Elsea [10] (a), Grogor'ev [12] (b) and Allibert [13] (c).

the $\alpha$-phase will sometimes exist in a $\mathrm{CoCr}$ alloy after fast cooling to RT at which the $\beta$-phase is also magnetic for its $\mathrm{Cr}$ content below 20 at\% [16].
The three diagrams in fig. 1 differ greatly with the position of the boundary between a single $\alpha$ region and an $\alpha+\sigma$ region. For sputtered films 
(usually about 20 at $\% \mathrm{Cr}$ ), the $\sigma$-phase should occur according to fig. 1(a), an intermetallic compound $\mathrm{Co}_{3} \mathrm{Cr}$ for fig. 1(b) and only an $\alpha$-phase if fig. 1(c) were correct. However, the experimental fact is that neither the $\sigma$-phase nor $\mathrm{Co}_{3} \mathrm{Cr}$ has been found in every $\mathrm{CoCr}$ film up to now. Hence, only fig. 1(c) can be regarded as being correct.

On tracing back these three diagrams to their experimental bases, it was found that the location of the line between the $\alpha$ and the $\alpha+\sigma$ regions in fig. 1(a) resulted from a micrographic study [10] of a 20 at $\% \mathrm{Cr}$ bulk sample. This sample was aged at $700^{\circ} \mathrm{C}$ and then quenched. Two stable phases, referred to as $\alpha$ and $\sigma$, were observed by optical microscopy. Thus the point of 20 at $\%$ and $700^{\circ} \mathrm{C}$ in the diagram was considered to lie in the twophase region. Present opinion is that it should be noted that a visible double-phase-like microstructure is only enough to support the fact that the sample exists in a certain double-phase region, but not what these two phases are nor where the boundary of the region is.

The data of fig. 1(b) were also based on metallographic observations [12]. The authors found coexistence of two phases in aged samples with compositions of 13 to 40 at $\mathrm{Cr}$. With the support of hardness and electric resistance tests, it was inferred that three intermetallic compounds, $\mathrm{Co}_{3} \mathrm{Cr}, \mathrm{CO}_{2} \mathrm{Cr}$ and $\mathrm{Co}_{3} \mathrm{Cr}_{2}$, appeared and formed three two-phase regions with $\alpha$ in the discussed composition range of the phase diagram. Because either hardness or resistance, like optical metallography, is only an indirect way of identifying phases, the existence of these three compounds has also remained uncertain.

Fig. 1(c) was drawn in 1978 [13] when the metallography could be improved by an electron probe for micro-area composition analysis (this was impossible at the time of the work of refs. $[10,12])$.

A sample of 46 at\% $\mathrm{Cr}$ [19] which was heat treated in the same way as mentioned in fig. 1(a) also showed two stable phases in it. Electron probe microanalysis (EPMA) indicated that one of them was of 40 at\% $\mathrm{Cr}$ and the other 55.7 at $\% \mathrm{Cr}$, corresponding to both sides of a double-phase region in the phase diagram.

Later work [17] with X-ray diffraction on the sputtered films over 44 at\% $\mathrm{Cr}$ content has revealed that two existing phases are $\alpha$ and $\sigma$. Therefore, the position of the boundary of an $\alpha+\sigma$ region in fig. $1(c)$ is credible.

The work of ref. [13] did not have the same study of detail in the range below 40 at\% $\mathrm{Cr}$ and $1000^{\circ} \mathrm{C}$. Recently in ref. [18] sputtered $\mathrm{Co}-\mathrm{Cr}$ has been analysed and from this a double-phase mixture area, ranging from $13-57$ at $\mathrm{Cr}$ below $500^{\circ} \mathrm{C}$ has been determined again, although the authors preferred the reality of the phase diagram from fig. 1(a), still without any direct evidence.

However, in such a range of 13-40 at\% $\mathrm{Cr}$, what really happens or what figs. 1(a) and (b) imply may be some other two-phase region than the $\alpha+\sigma$ one. It requires more investigation.

\section{Sputtered CoCr films}

It is known from experiments that in general the magnetic properties of sputtered $\mathrm{CoCr}$ films deviate from those of the bulk (e.g. ref. [21]). They will also possess a higher saturation magnetization $\left(M_{\mathrm{s}}\right)$ than the bulk alloys with the same composition; in other words, the curve of $M_{s}$ vs. at $\% \mathrm{Cr}$ in the case of these films will deviate upwards from the so-called S-P curve [13,20-22]. The general behaviour is shown in fig. 2 .

This phenomenon is attributed to segregation in the films which produces Co-rich and Cr-rich

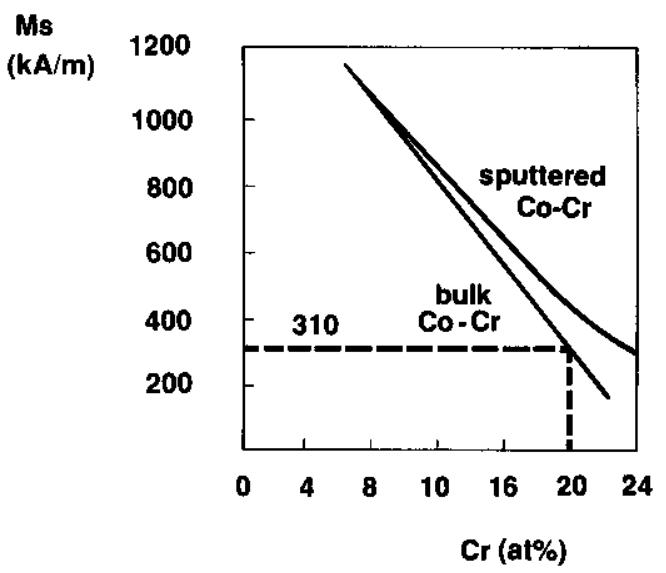

Fig. 2. Magnetization as function of $\mathrm{Cr}$-content for $\mathrm{CoCr}$ bulk (S-P-curve) and sputtered films [21]. 

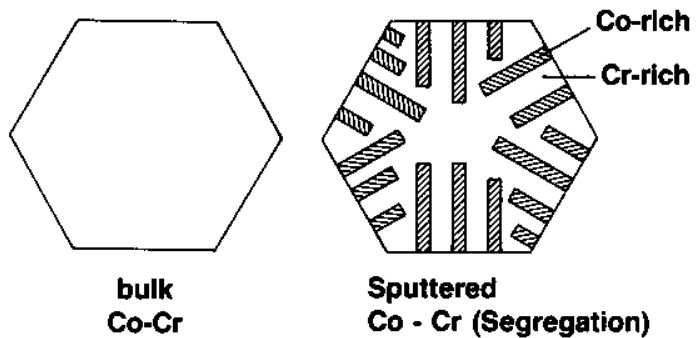

Fig. 3. A schematic presentation (after Maeda [23]) of $\mathrm{Cr}$ segregation in one column of a sputtered $\mathrm{CoCr}$ film.

areas with the same hcp lattice as the $\alpha$-phase.

In fig. 3 the schematically segregated structure as observed by Maeda et al. [23] applying a selective etching method and TEM observations is given for sputtered $\mathrm{CoCr}$ films.

Also in ref. [24] clear evidence of such a segregation is given. By electron probe microanalyses Rogers et al. [25] have shown a marked enrichment of $\mathrm{Cr}$ at the columnar boundaries in films prepared under totally different conditions to those in ref. [23].

Very recently similar segregated structures were also found in evaporated $\mathrm{CoCr}$ films [26].

Although the Cr-rich part is more than 25 at $\%$ $\mathrm{Cr}$ and becomes nonmagnetic in accordance with the $S-P$ curve, a great increase of $M_{s}$, from the Co-rich part will be enough to make up for this lack. As a result, the average value of $M_{\mathrm{s}}$ for a segregated film becomes higher.

It is also known that during sputtering the surface temperature $\left(T_{\text {sur }}\right)$ of a film is quite different from that of the substrate $\left(T_{s}\right)$ [27]. The bombardment exerted by various particles on the surface results in a much higher $T_{\text {sur }}$. As they reach the substrate from a target, the sputtered atoms will actually be crystallized at $T_{\text {sur }}$ and then rapidly cooled down to $T_{\mathrm{s}}$ when successive new surface layers cover them. This is a quench-like process which can retain some characteristics of high temperature crystallization at room temperature.

\section{Quench experiments on ribbons}

In order to simulate the sputtering process and study the regularity of segregation in the $\mathrm{CoCr}$ system, two ribbons with different compositions were used for quench experiments.

In fact the initial ribbons were also the product of a heavy quench (fast cooling from melt) and could be investigated on their magnetic properties for a close comparison with sputtered films. Because of its much higher resistance to oxidation than the films, a ribbon can receive a series of heat treatments in order to observe the influence of the quench temperature on the magnetic properties and phase state in the $\mathrm{CoCr}$ system.

\section{Experimental}

Two kinds of ribbons, $\mathrm{Co}_{80} \mathrm{Cr}_{20}$ and $\mathrm{Co}_{73} \mathrm{Cr}_{27}$ with thicknesses of $20-30 \mu \mathrm{m}$ and widths of $6-10$ $\mathrm{mm}$, were chosen because 20 at $\% \mathrm{Cr}$ is the commonest content of the films used and $27 \mathrm{at} \% \mathrm{Cr}$ is just above the transition point of ferro- to paramagnetism for films at RT. The exact compositions of the ribbons were measured by XRF as 19.8 and 27.2 at\% $\mathrm{Cr}$.

They were prepared by a spun-melt method. Samples cut from the ribbons were heated at certain elevated temperatures to get them stable structures and then quenched to RT. Heating time depended on the temperatures applied, i.e., a longer (or shorter) period at a high (or low) temperature, in the range of 5-60 min. There were two ways of applying heat treatment; one was to heat a sample in the open-air and to quench it by putting it directly in an environment at room temperature, which took a few seconds to get it completely cooled; the other was to enclose the sample in a quartz tube of $\varnothing 10 \times 80 \mathrm{~mm}^{2}$ with a vacuum pressure of $10^{-3}$ mbar, before heating and to quench it in water after the heating procedure. Before and after heat treatment, the magnetization and phase configuration of both ribbons were measured with VSM and X-ray diffraction, respectively. The samples for $\mathrm{X}$-ray diffraction was ribbon-like, about $20 \mathrm{~mm}$ long, and the reflection data were obtained at $40 \mathrm{kV} / 30 \mathrm{~mA}$ by means of $\mathrm{Cu}-\mathrm{K}_{\alpha}$ radiation.

The microstructures of the ribbons were observed by SEM. During preparation for SEM observations the samples were polished mechanically and then etched for $1 \mathrm{~h}$ in a solution of $0.6 \mathrm{~N}-\mathrm{HCl}$ and $0.067 \mathrm{~N}-\mathrm{HNO}_{3}$ at a volume ratio of $1: 1$. 


\section{Experimental results}

\section{1. $\mathrm{Co}_{80} \mathrm{Cr}_{20}$ ribbon}

The measured $\mathrm{X}$-ray diffraction data $(2 \theta, d)$ for both types of ribbon compositions are given in table 1 as well as their identifications. The relative intensities are given as a function of the quench temperatures $\left(700,800\right.$ and $\left.1000^{\circ} \mathrm{C}\right)$. While RT (= room temperature) indicates the as-ribbon state. For the relative intensity of a peak compared with the others in the same pattern we used the letters of strong, middle or weak. The second letter is the relative intensity of a peak compared with the same peak in the other patterns for the same type of ribbon.

The X-ray diffraction patterns obtained from the $\mathrm{Co}_{80} \mathrm{Cr}_{20}$ ribbon are shown in fig. 4. It was found from fig. 4(a) that a crystallization with a matrix of $\beta$-phase and a balance of $\alpha$-phase had taken place in the as-ribbon sample which had an initial $M_{\mathrm{s}}$ of $180 \mathrm{kA} / \mathrm{m}$ at $\mathrm{RT}$, which is much lower than the value of $310 \mathrm{kA} / \mathrm{m}$ for its bulk (see fig. 2).

It was the presence of so much $\beta$-phase, considered nonmagnetic because of its $\mathrm{Cr}$ content of 20 at\%, that reduced the ribbon's magnetization. The heating temperature dependence of $M_{\mathrm{s}}$ and $H_{\mathrm{c}}$ for

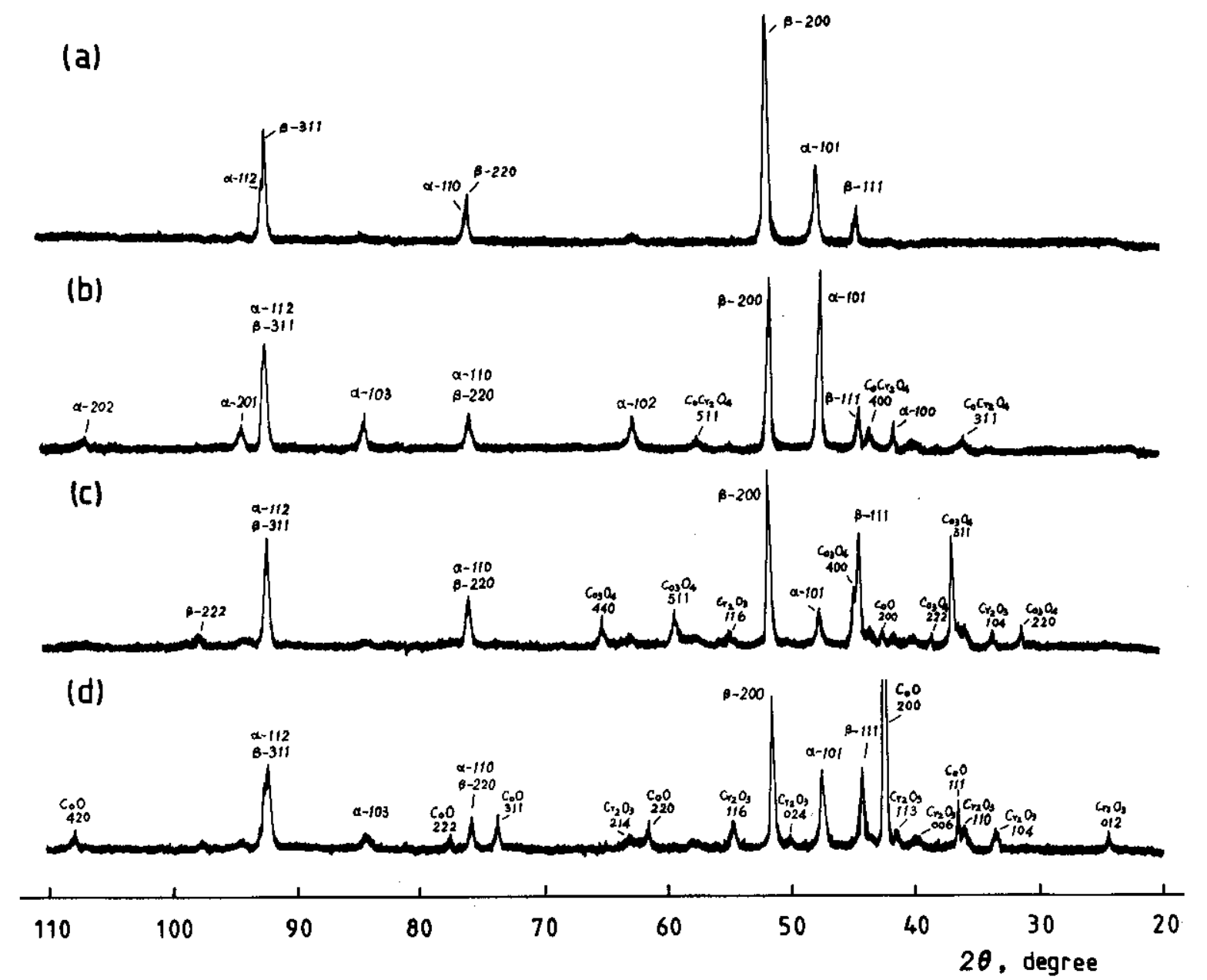

Fig. 4. X-ray diffraction data from $\mathrm{Co}_{80} \mathrm{Cr}_{20}$ ribbons before (a) and after (b-d) quenching in open air, at different temperatures: (b) $700^{\circ} \mathrm{C} \times 15 \mathrm{~min}$, (c) $800^{\circ} \mathrm{C} \times 10 \mathrm{~min}$ and (d) $1000^{\circ} \mathrm{C} \times 5 \mathrm{~min}$. 
Table 1

X-ray data of the used ribbons

\begin{tabular}{|c|c|c|c|c|c|c|c|c|c|}
\hline \multirow{3}{*}{$\begin{array}{l}2 \theta \\
\left({ }^{\circ}\right) \\
\end{array}$} & \multirow{3}{*}{$\begin{array}{l}d \\
(\AA)\end{array}$} & \multirow{3}{*}{$\begin{array}{l}\text { Phases and } \\
\text { reflections }\end{array}$} & \multicolumn{7}{|c|}{ Relative intensities } \\
\hline & & & \multicolumn{4}{|c|}{20 at $\% \mathrm{Cr}$} & \multicolumn{3}{|c|}{27 at $\% \mathrm{Cr}$} \\
\hline & & & RT & $700^{\circ} \mathrm{C}$ & $800^{\circ} \mathrm{C}$ & $1000^{\circ} \mathrm{C}$ & $\overline{\mathrm{RT}}$ & $700^{\circ} \mathrm{C}$ & $1000^{\circ} \mathrm{C}$ \\
\hline & & $\alpha-(h c p)$ & & & & & & & \\
\hline 41.39 & 2.1795 & $(100)$ & -- & w- & -- & -- & -- & $\mathrm{m}-$ & -- \\
\hline 44.54 & 2.0323 & $(002)$ & -- & -- & -- & -- & w- & -- & w- \\
\hline 47.34 & 1.9184 & (101) & sw & ss & $\mathrm{mw}$ & $\mathrm{mm}$ & sw & ss & sw \\
\hline 62.44 & 1.4860 & (102) & -- & $\mathbf{m}-$ & -- & -- & w- & s- & $w-$ \\
\hline 76.00 & 1.2514 & (110) & w- & w- & w- & $\mathbf{w}-$ & m- & $\mathrm{m}-$ & $\mathrm{m}-$ \\
\hline 84.23 & 1.1485 & (103) & -- & ws & -- & ww & $w-$ & $\mathrm{m}-$ & w- \\
\hline 92.20 & 1.0690 & (112) & $\mathbf{m}-$ & m- & m- & m- & s- & s- & $\mathrm{m}-$ \\
\hline 94.17 & 1.0517 & (201) & -- & w- & -- & -- & -- & m- & -- \\
\hline \multirow[t]{2}{*}{106.85} & 0.9591 & $(202)$ & -- & $\mathbf{w -}$ & -- & -+ & $-\infty$ & $\mathbf{w}-$ & -- \\
\hline & & $\beta-(f c c)$ & & & & & & & \\
\hline 44.19 & 2.0478 & (111) & $\mathrm{mm}$ & wm & ss & $\mathrm{mm}$ & $\mathrm{sm}$ & ww & ss \\
\hline 51.46 & 1.7741 & $(200)$ & ss & sm & sm & $\mathrm{sm}$ & ss & $\mathrm{mw}$ & sm \\
\hline 75.85 & 1.2531 & $(220)$ & m- & w- & m- & w- & m- & $\mathbf{w}-$ & m- \\
\hline 92.19 & 1.0691 & (311) & s- & $\mathrm{m}-$ & s- & m- & m- & $w-$ & m- \\
\hline 97.69 & 1.0230 & (222) & $\mathbf{m}-$ & -- & w- & -- & w- & -- & w- \\
\hline 35.72 & 2.5116 & $\begin{array}{c}\mathrm{CoCr}_{2} \mathrm{O}_{4} \\
(311)\end{array}$ & -- & ws & ww & -- & -- & w- & -- \\
\hline 43.31 & 2.0872 & $(400)$ & -- & ws & ww & -- & -- & w- & -- \\
\hline 57.35 & 1.6053 & (511) & -- & $\mathbf{w -}$ & -- & -- & -- & w- & -- \\
\hline 31.17 & 2.8666 & $\begin{array}{c}\mathrm{Co}_{3} \mathrm{O}_{4} \\
(220)\end{array}$ & -- & -- & w- & -- & -- & -- & -- \\
\hline 36.75 & 2.4434 & (311) & -- & -- & s- & -- & -- & -- & $-m$ \\
\hline 38.47 & 2.3382 & $(222)$ & -- & -- & $\mathbf{w}-$ & -- & -- & -- & -- \\
\hline 44.63 & 2.0286 & $(400)$ & -- & -- & m- & -- & -- & -- & -- \\
\hline 59.20 & 1.5593 & $(511)$ & -- & -- & m- & -- & -- & -- & -- \\
\hline 65.17 & 1.4302 & $(440)$ & -- & -- & $\mathbf{w}-$ & -- & -- & -- & -- \\
\hline 24.47 & 3.6346 & $\begin{array}{c}\mathrm{Cr}_{2} \mathrm{O}_{3} \\
(012)\end{array}$ & -- & -- & -- & $w_{-}$ & -- & -- & $\mathbf{m}-$ \\
\hline 33.50 & 2.6726 & (104) & -- & -- & ww & ws & -- & -- & m- \\
\hline 36.05 & 2.4892 & $(110)$ & -- & -- & ww & ws & -- & -- & $w-$ \\
\hline 39.80 & 2.2629 & $(006)$ & -- & -- & -- & w- & -- & -- & $\mathbf{w}-$ \\
\hline 41.47 & 2.1756 & (113) & -- & -- & w- & w- & -- & -- & $w-$ \\
\hline 50.15 & 1.8175 & (024) & -- & -- & -- & w- & -- & -- & $\mathbf{w}-$ \\
\hline 54.75 & 1.6751 & (116) & -- & -- & w- & w- & -- & -- & m- \\
\hline \multirow[t]{2}{*}{63.20} & 1.4700 & (214) & -- & -- & -- & w- & -- & -- & $w-$ \\
\hline & & $\mathrm{CoO}$ & & & & & & & \\
\hline 36.50 & 2.4596 & (111) & -- & -- & -- & $\mathrm{m}-$ & -- & -- & -- \\
\hline 42.40 & 2.1300 & $(200)$ & -- & -- & ww & ss & -- & -- & s- \\
\hline 61.60 & 1.5043 & $(220)$ & -- & -- & -- & w- & -- & -- & -- \\
\hline 73.80 & 1.2829 & (311) & -- & -- & -- & w- & -- & -- & -- \\
\hline 77.60 & 1.2292 & $(222)$ & -- & -- & -- & $w-$ & -- & -- & -- \\
\hline 107.96 & 0.9523 & (420) & -- & -- & -- & $w-$ & -- & -- & -- \\
\hline
\end{tabular}

samples quenched in the open air is shown in fig. 5 in which points $a, b, c$ and $d$ correspond to the four patterns of fig. 4 , respectively. In this figure
$H_{\mathrm{c} \perp}$ means the coercivity measured perpendicular to the ribbon surface while $H_{\mathrm{c} \|}$ is determined in-plane of the ribbon. Quenching after heating 


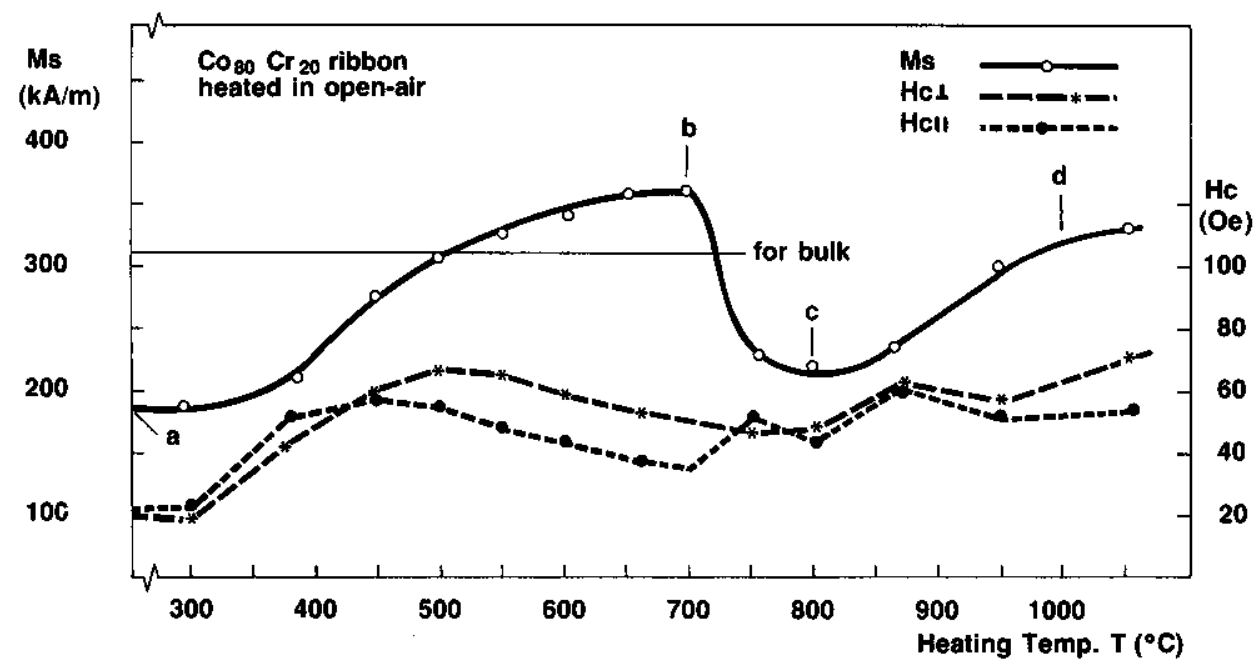

Fig. 5. $M_{s}$ and $H_{c}$ as a function of the heating in the open air of a $\mathrm{Co}_{80} \mathrm{Cr}_{20}$ ribbon.

below $350^{\circ} \mathrm{C}$ makes no difference to the $M_{\mathrm{s}}$ of the sample.

The curve of $M_{\mathrm{s}}$ rises monotonously from 350 to $700^{\circ} \mathrm{C}$. It is considered that the $\beta$ phase is converted into $\alpha$, in accordance with the phase diagrams of fig. 1 where this temperature range is situated in a single $\alpha$ region. This is also confirmed by the X-ray pattern of the sample quenched from $700^{\circ} \mathrm{C}$, as shown in fig. 4(b). The peak of $\beta-(200)$ decreases with the growing peak of $\alpha$-(101), compared with fig. 4(a). The $M_{\mathrm{s}}$ curve of fig. 5 falls dramatically from 700 to $800^{\circ} \mathrm{C}$. In this temperature range the phase diagrams indicate a transition of an $\alpha$ region to a $\beta$ region so that $\beta$ becomes stable by a reaction of $\alpha$ to $\beta$. The $X$-ray pattern of a sample quenched from $800^{\circ} \mathrm{C}$ (see fig. 4(c)) supports the expected situation, because its $\beta$-(111) peak increases greatly and $\alpha$-(101)

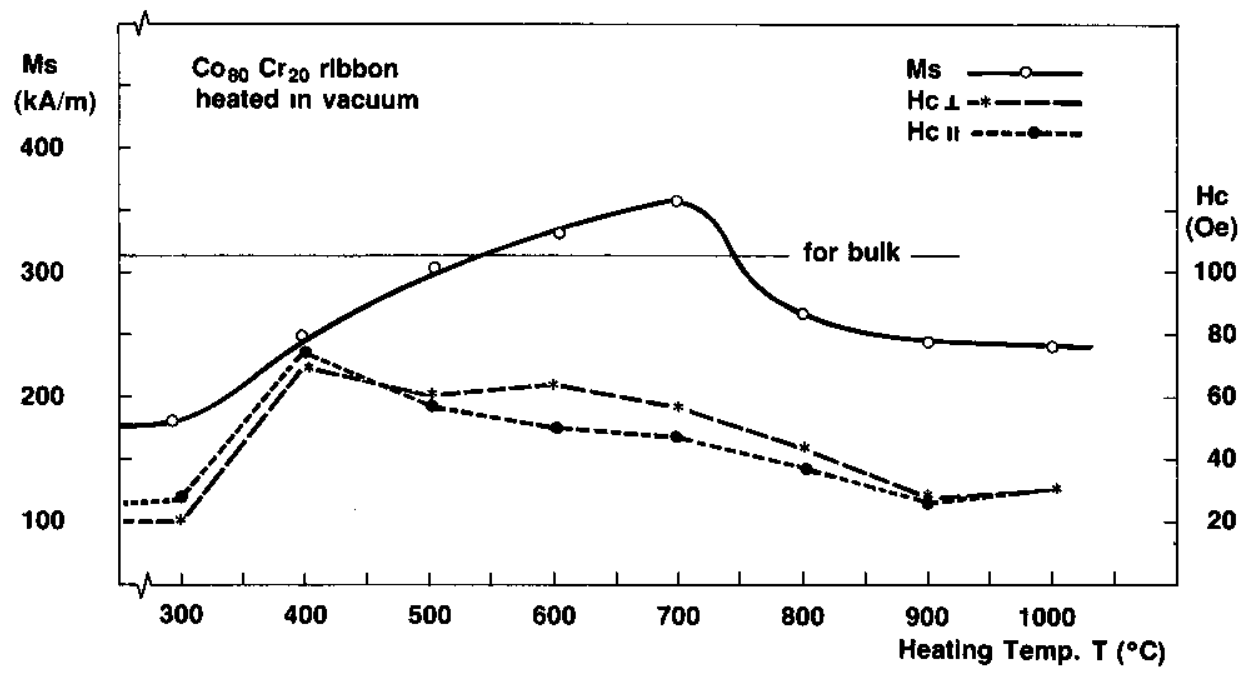

Fig. 6. $M_{\mathrm{s}}$ and $H_{\mathrm{c}}$ as a function of the heating in a vacuum of a $\mathrm{Co}_{80} \mathrm{Cr}_{20}$ ribbon. 

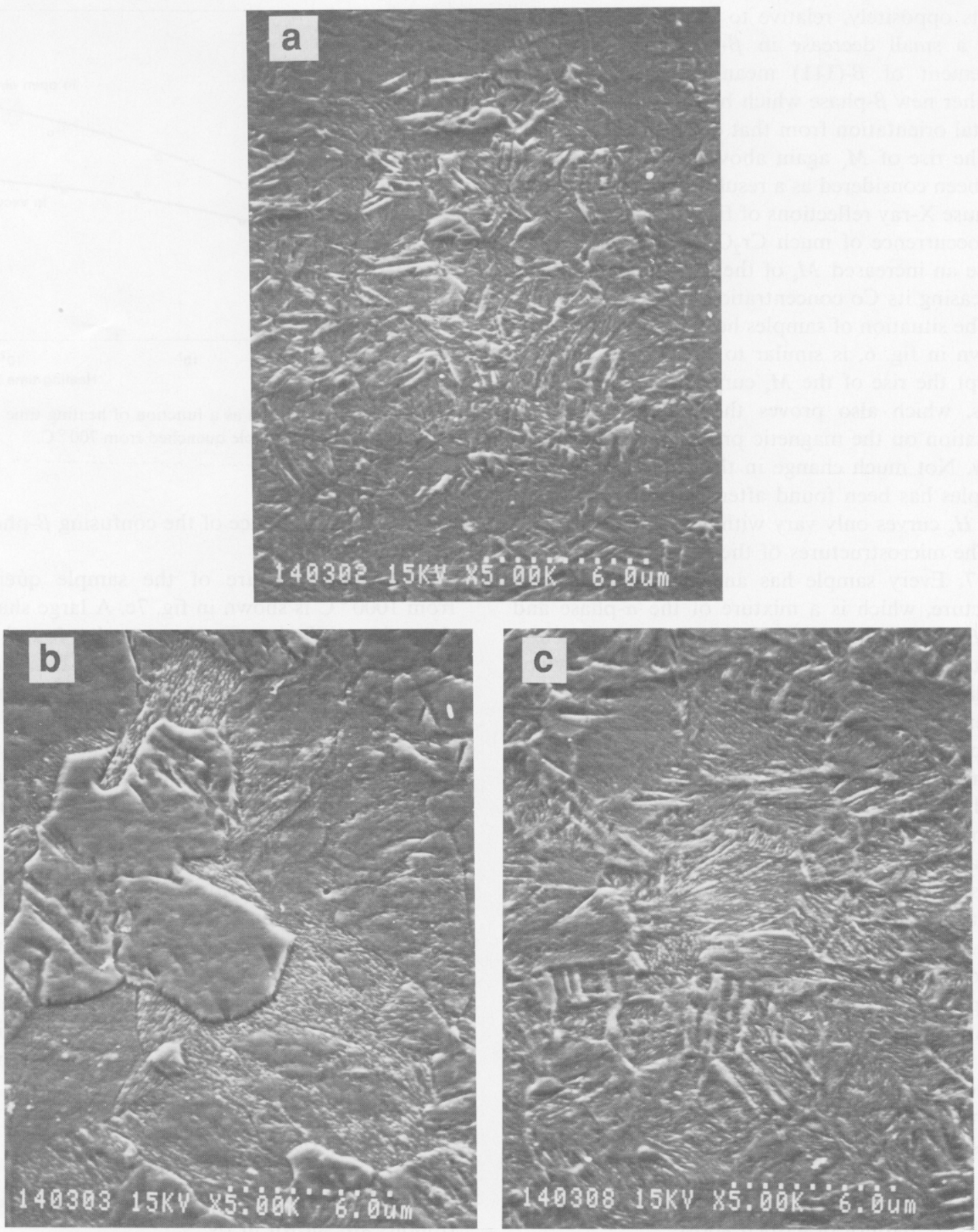

Fig. 7. The microstructures of $\mathrm{Co}_{80} \mathrm{Cr}_{20}$ as-ribbon (a) and quenched in open-air after heating $700^{\circ} \mathrm{C} \times 15$ min (b) and $1000^{\circ} \mathrm{C} \times$ 5 min (c). 
reacts oppositely, relative to fig. $4(a)$. It is noted that a small decrease in $\beta-(200)$ and the large increment of $\beta$-(111) mean the occurrence of another new $\beta$-phase which behaves in a different crystal orientation from that of its original.

The rise of $M_{\mathrm{s}}$ again above $800^{\circ} \mathrm{C}$ (see fig. 5) has been considered as a result of heavy oxidation, because $X$-ray reflections of fig. $\mathbf{4 ( d )}$ have revealed the occurrence of much $\mathrm{Cr}_{2} \mathrm{O}_{3}$ oxide which could cause an increased $M_{s}$ of the sample by relatively increasing its Co concentration.

The situation of samples heated in a vacuum, as shown in fig. 6 , is similar to that in the open-air except the rise of the $M_{s}$ curve for high temperatures, which also proves the real effect of the oxidation on the magnetic properties of the $\mathrm{CoCr}$ alloy. Not much change in the coercivity $\left(H_{c}\right)$ of samples has been found after any heat treatment. The $H_{\mathrm{c}}$ curves only vary within 20-70 Oe.

The microstructures of the ribbons is shown in fig. 7. Every sample has an acicular and rough structure, which is a mixture of the $\alpha$-phase and the $\beta$-phase. The directions of the mixed acicular crystallite are consistent in a local zone, which implies a correlation of crystal orientation between $\alpha$ and $\beta$. This kind of zone corresponds to the primary grain of a single $\beta$-phase in which the secondary $\alpha$-phase has a related orientation and produces the mixed structure.

In fig. 7a the directions of acicular grains for the as-ribbon sample seem random and indicate the small size of their primary $\beta$-phase grains; a character of an alloy heavily quenched from the melt. Besides the acicular structure, many bigger, smoother and brighter grains also exist in the sample, they are nearly pure $\alpha$-phase. All their sizes are much more than $100 \mathrm{~nm}$ as can be easily seen in the figure. This effect indicates the phenomenon of heavy crystallization.

In fig. $7 \mathrm{~b}$ for the sample quenched from $700^{\circ} \mathrm{C}$, the smooth grains grow much larger and the total area of the mixed structure is reduced, so that a phase transition of $\beta$ to $\alpha$ can be considered as the X-ray pattern described above.

Observation of a segregated $\alpha$-phase structure had been expected for this sample, but this was not the case due to the small magnification of the

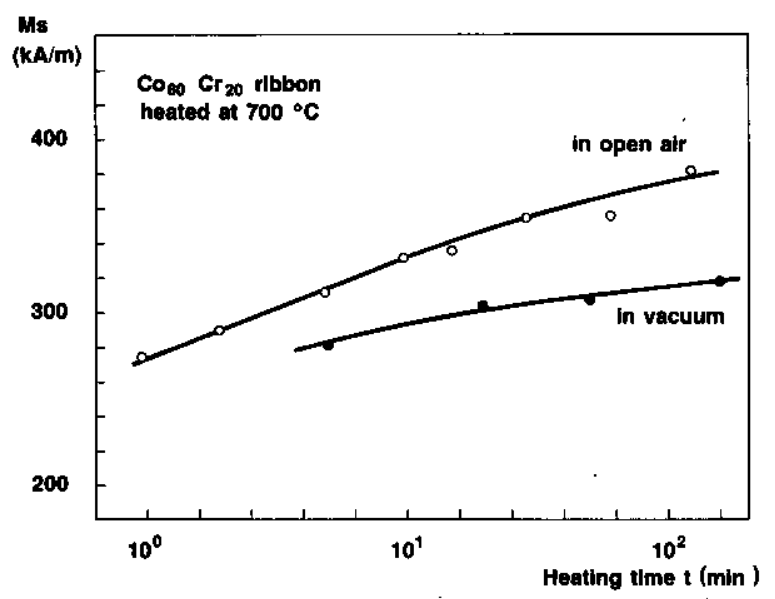

Fig. 8. The magnetization as a function of heating time for the $\mathrm{Co}_{80} \mathrm{Cr}_{20}$ sample quenched from $700^{\circ} \mathrm{C}$.

SEM and the presence of the confusing $\beta$-phase in the microstructure.

The microstructure of the sample quenched from $1000^{\circ} \mathrm{C}$ is shown in fig. 7c. A large shape of the primary $\beta$-phase grains can be found indirectly. This is because the sample had been held at such a high temperature before quenching and the $\beta$-grains had grown quickly.

The sample quenched from $700^{\circ} \mathrm{C}$ has a maximum of $M_{s}$; the effect of the heating time on this sample has been investigated and is shown in fig. 8.

In the case of open-air quenching, the curve rises monotonically with the time for two reasons: phase transition and oxidation. In the case of quenching in vacuum, the curve also rises but only slightly and this means that only a phase transition effect takes place, while the difference of $15-35 \mathrm{kA} / \mathrm{m}$ between these two curves implies an oxidation effect which has been confirmed by the existence of $\mathrm{CoCr}_{2} \mathrm{O}_{4}$ reflections of fig. 4(b).

\section{2. $\mathrm{Co}_{73} \mathrm{Cr}_{27}$ ribbons}

The X-ray diffraction data of these kinds of ribbons are shown in fig. 9.

According to pattern (a), the as-ribbon sample was also in a crystalline form of $\alpha+\beta$, but the amount of $\alpha$ is larger, being relative to the initial 
(a)

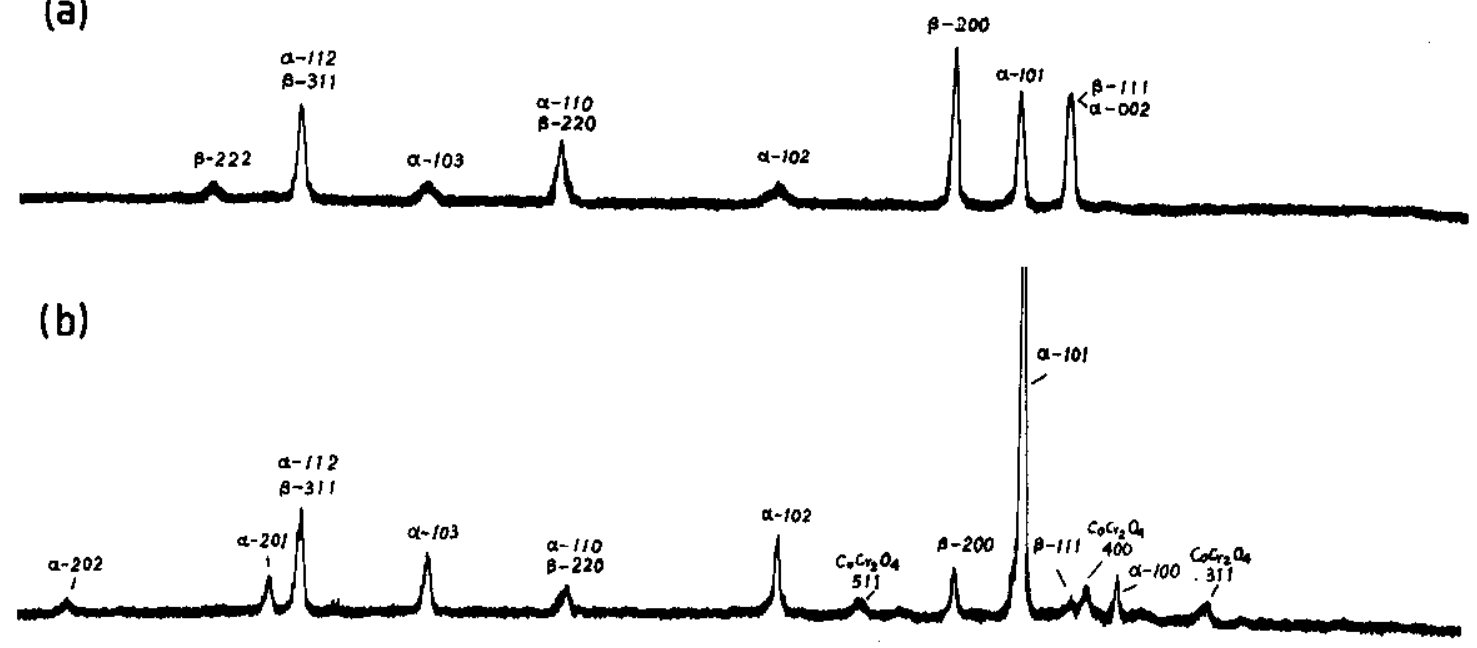

(c)

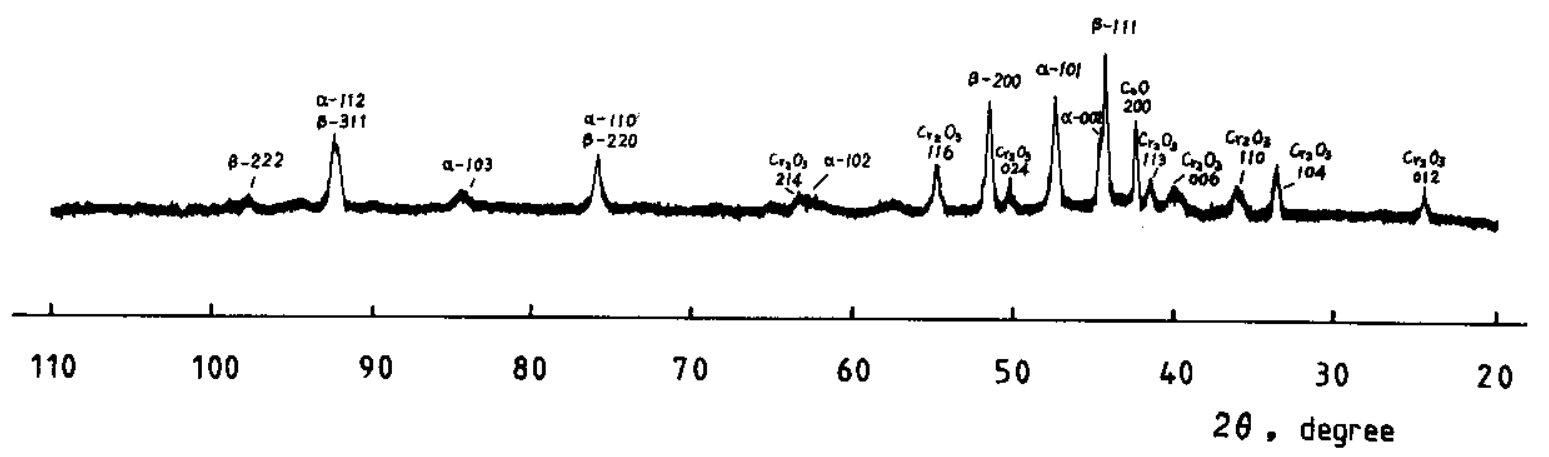

Fig. 9. X-ray diffraction data from $\mathrm{Co}_{73} \mathrm{Cr}_{27}$ as-ribbon (a) and quenched in the open air after heating $700^{\circ} \mathrm{C} \times 15 \mathrm{~min}$ (b) and $1000^{\circ} \mathrm{C} \times 5 \mathrm{~min}(\mathrm{c})$.

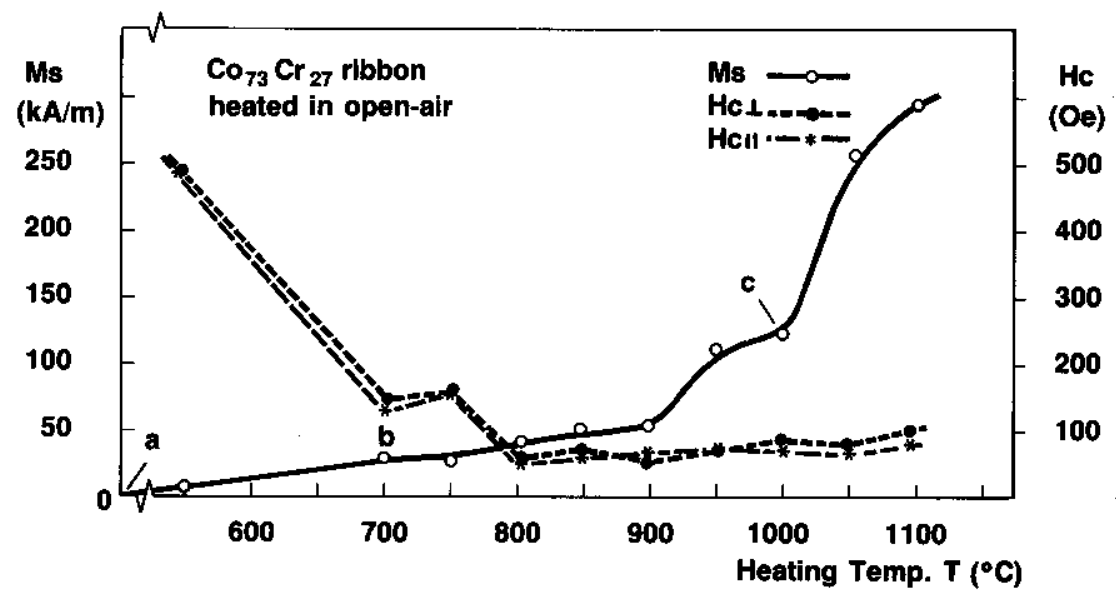

Fig. 10. $M_{s}$ and $H_{c}$ dependence of the heating in the open' air of $\mathrm{Co}_{73} \mathrm{Cr}_{27}$ ribbons. 
state of 20 at $\mathrm{Cr}$ ribbon, because of a much reduced $\beta-(200)$ reflection and the appearance of new reflections of $\alpha-(102)$ and $\alpha-(103)$. Pattern (b) of the sample quenched from $700^{\circ} \mathrm{C}$ shows much more $\alpha$-phase than in the same pattern of fig. 4 for the 20 at $\% \mathrm{Cr}$ ribbon. However, a little $\beta$-phase and oxide still remain in it. Pattern (c) of fig. 9 describing the $(20$ at $\% \mathrm{Cr}$ ) sample quenched from $1000^{\circ} \mathrm{C}$ is similar to the corresponding pattern of fig. 4 , but the amount of $\mathrm{CoO}$ is relatively reduced and the orientation of $\beta$ changes due to stronger $\beta$-(111) and weaker $\beta$-(200) reflections.

The quenching results after heating in open air are shown in fig. 10. It can be seen from this that its initial state is nonmagnetic. In the case of open air quenching, the $M_{s}$ curve (in which points $\mathrm{a}, \mathrm{b}$ and c correspond to three X-ray patterns of fig. 9) rises greatly with increased temperature, especially above $900^{\circ} \mathrm{C}$. Therefore anomalous and high values of $M_{\mathrm{s}}$ can be thought as the reason for oxidation with the element $\mathrm{Cr}$ if the curve is compared with the other in the case of a vacuum. The latter curve (see fig. 11) has a weak $M_{\mathrm{s}}$ of $5-10 \mathrm{kA} / \mathrm{m}$, which is almost constant for the whole temperature scale, and could be the reason for the phase transition.

The $H_{\mathrm{c}}$ of the as-ribbon sample can be referred to as infinite for its nonmagnetic nature. After heating in both ways below $700^{\circ} \mathrm{C}, H_{\mathrm{c}}$ values decrease dramatically with the occurrence of weak magnetism. However, heating above $800^{\circ} \mathrm{C}$ does not enable a continuous reduction of $H_{c}$ values which remain around 50-100 Oe and are independent of increasing magnetization.

It can be concluded from a comparison of both ribbons, that the 27 at $\mathrm{Cr}$ one is more liable to oxidize. In fig. 12, the heating time dependence of $M_{\mathrm{s}}$ of the ribbon quenched from $700^{\circ} \mathrm{C}$ also supports this point. In this figure both relations are given for quenching in open air and in vacuum.

The microstructure of the sample quenched from $700^{\circ} \mathrm{C}$ is shown in fig. 13. Its smooth matrix is $\alpha$-phase in which there are a lot of other dot-like grains, as can be clearly seen in fig. 13b. They are

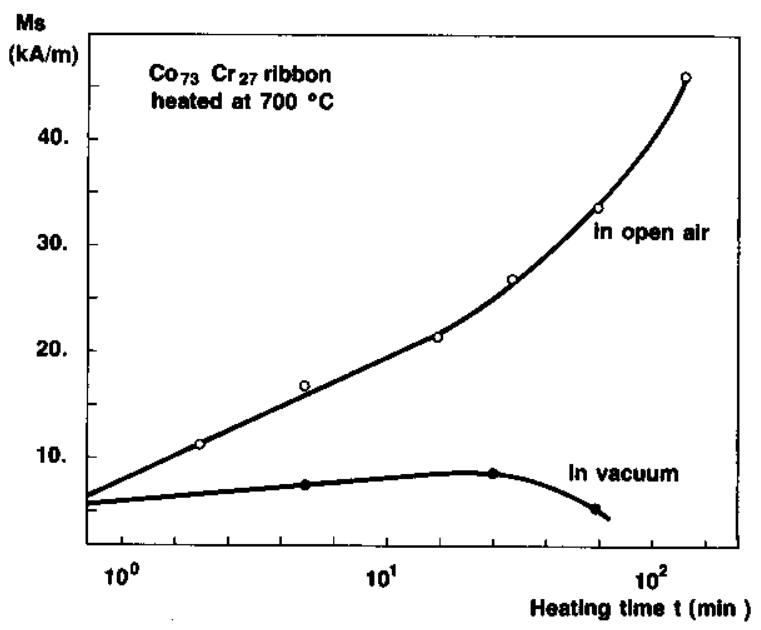

Fig. 12. Magnetization as a function of the heating time for $\mathrm{Co}_{73} \mathrm{Cr}_{27}$ ribbon quenched from $700^{\circ} \mathrm{C}$ in the open air and a vacuum.

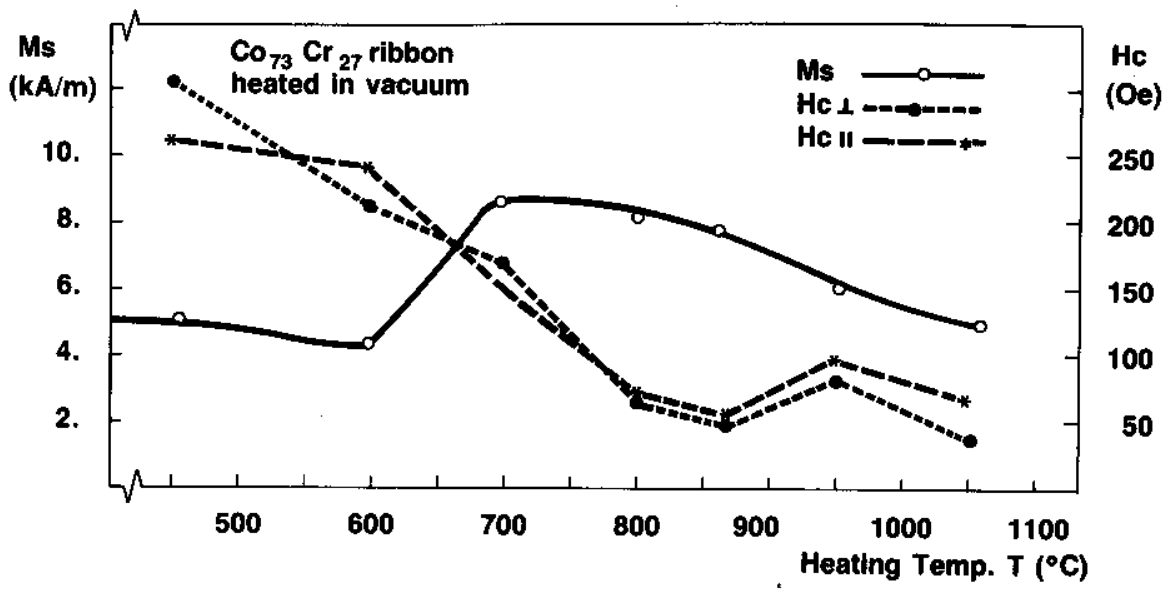

Fig. 11. $M_{s}$ and $H_{c}$ dependences of the heating in vacuum of a $\mathrm{Co}_{73} \mathrm{Cr}_{27}$ ribbons. 

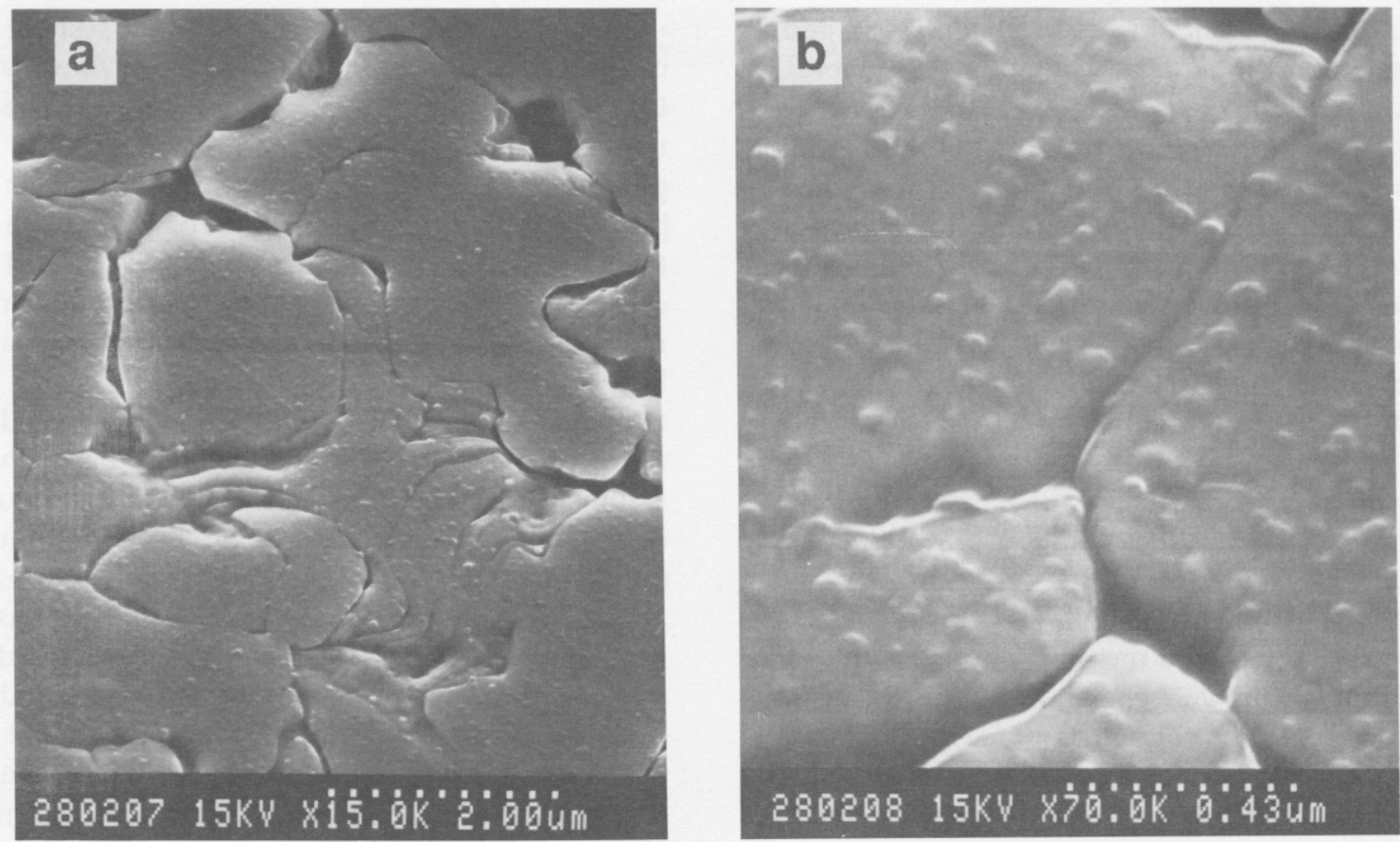

Fig. 13. The microstructure of a $\mathrm{Co}_{73} \mathrm{Cr}_{27}$ ribbon quenched in the open air after $700^{\circ} \mathrm{C} \times 15$ min at low (a) and high (b) magnification.

considered to be the residual of the $\beta$-phase. The volume ratio of $\alpha$ to $\beta$ is in agreement with the $\mathrm{X}$-ray diffraction result (see relative reflection intensities). It is worth noting that elements in the $\mathrm{CoCr}$ system are so mobile during heating in the open air that they will combine with oxygen in quite different forms at varying temperatures.

Information on oxides from the current work is listed in table 2. The literature [28] on the oxidation of $\mathrm{CoCr}$ alloy pointed out that the controlling factor is a competition between the higher oxidation potential of $\mathrm{Cr}$ relative to $\mathrm{Co}$ and a higher diffusivity of $\mathrm{Co}$ in the oxide relative to $\mathrm{Cr}$. At $700^{\circ} \mathrm{C}$, the ribbon becomes oxidized on its outer

Table 2

Oxides in $\mathrm{CoCr}$ ribbons heated in open air

\begin{tabular}{llcl}
\hline Oxide & Crystal lattice & Existing temp. & Effect on $M_{\mathrm{s}}$ of $\alpha$ \\
\hline $\mathrm{CoCr}_{2} \mathrm{O}_{4}$ & cubic & $700^{\circ} \mathrm{C}$ & increase \\
$\mathrm{Co}_{3} \mathrm{O}_{4}$ & cubic & $800^{\circ} \mathrm{C}$ & decrease \\
$\mathrm{Cr}_{2} \mathrm{O}_{3}$ & hexagonal & $1000^{\circ} \mathrm{C}$ & increase \\
$\mathrm{CoO}$ & fcc & $1000^{\circ} \mathrm{C}$ & decrease \\
\hline
\end{tabular}

surface because of slow diffusion. $\mathrm{Co}$ and $\mathrm{Cr}$ of the surface part are combined with oxygen simultaneously, hence the oxide $\mathrm{CoCr}_{2} \mathrm{O}_{4}$, which can be seen equally as $\mathrm{CoO}+\mathrm{Cr}_{2} \mathrm{O}_{3}$, appears to have and implies a preferential oxidation of $\mathrm{Cr}$ above $\mathrm{Co}$ with respect to the average composition of the ribbon. At $800^{\circ} \mathrm{C}$, the ribbon has a faster diffusion of Co toward its surface so that Co Oxide $\left(\mathrm{Co}_{3} \mathrm{O}_{4}\right)$ forms the greater part. At $1000^{\circ} \mathrm{C}$, oxygen can diffuse itself inwards from the surface and meets a fresh part of the alloy, as reported in ref. [29], so internal oxidation occurs through the ribbon having the appearance of $\mathrm{CoO}$ and $\mathrm{Cr}_{2} \mathrm{O}_{3}$.

\section{Discussion}

Results from the investigated $\mathrm{Co}_{80} \mathrm{Cr}_{20}$ ribbon are encouraging. It can be seen in fig. 5 that, in the range of 520 to $730^{\circ} \mathrm{C}$, the $M_{\mathrm{s}}$ of a quenched $\mathrm{Co}_{80} \mathrm{Cr}_{20}$ sample is more than the value for its bulk. Whereas the corresponding X-ray diffraction pattern has revealed only a little oxide occurring 
which has a weak effect on the ribbon, and a considerable amount of $\beta$-phase in the sample.

A composition segregation in the magnetic $\alpha$ phase can be inferred by the fact that a sample possesses such a high value of $M_{\mathrm{s}}$ even when it contains a large amount of the (nonmagnetic) $\beta$ phase. There is an assumption that in this temperature range a phase separation region of the $\mathrm{CoCr}$ phase diagram exists in which $\alpha$ will be decomposed automatically into its two subphases, called $\alpha_{1}$ and $\alpha_{2}$, with the same hcp lattice and different compositions. This idea was proposed for the first time in ref. [30].

The process of the separation has been considered to make the free energy of the alloy system lower, one of the two subphases is magnetic for its lower $\mathrm{Cr}$ content and the others nonmagnetic. The situation is drawn schematically in fig. 14 by dashed lines. The formation of $\alpha_{1}$ and $\alpha_{2}$ should be stable, but under diffusion control, which requires a certain time to finish its process fully. The compositions of $\alpha_{1}$ and $\alpha_{2}$ are decided by both side lines of the phase separation region in the phase diagram, respectively. Their amounts obey

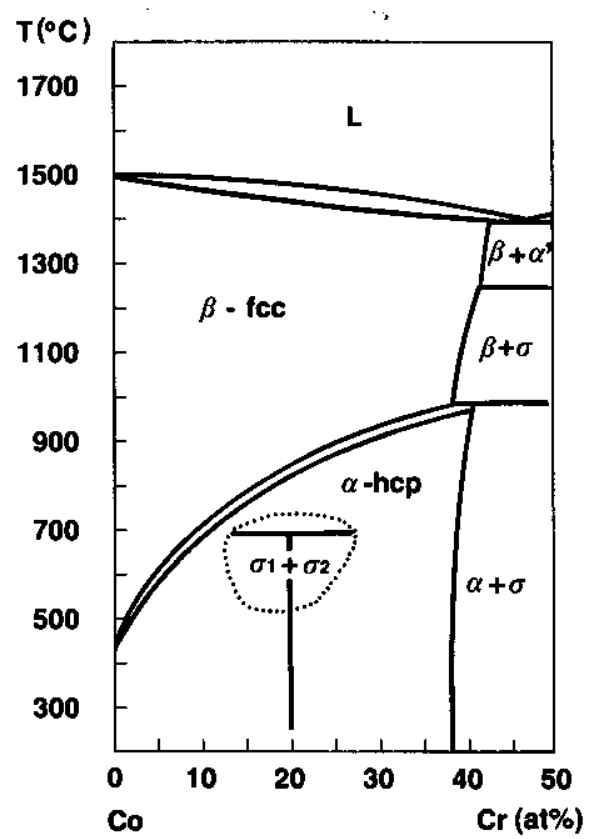

Fig. 14. A schematic phase separation region of $\alpha_{1}+\alpha_{2}$ in a $\mathrm{CoCr}$ phase diagram. the basic lever rule for a binary alloy system. As mentioned above, the $\mathrm{Co}_{73} \mathrm{Cr}_{27}$ ribbon shows very little magnetization after a quench, so its $\mathrm{Cr}$ content could be close to the right boundary of the phase separation region. In addition, the literature [17] claims that the $M_{\mathrm{s}}$ deviation of the films from their S-P curve only occurred above a critical $\mathrm{Cr}$ content of 13 at $\%$. Therefore, the composition range of the separation region can be estimated from 13 to 30 at\% $\mathrm{Cr}$. On the other hand, its temperature range is about $520-730^{\circ} \mathrm{C}$, according to the results of fig. 5 . It is interesting that such an assumed region just coincides with the unknown double-phase region implied from the comment on the published phase diagrams as mentioned above. This assumption can be used for interpreting experiments. If a $\mathrm{CoCr}$ ribbon is heated in the separation region for a long enough period of time, its $\alpha$-phase will decompose into $\alpha_{1}$ and $\alpha_{2}$ which can be kept at RT by a successive quench. Consequently segregation from phase separation will result in an increase of $M_{\mathrm{s}}$.

During sputtering, if $T_{\mathrm{s}}$ is proper, $T_{\text {sur }}$ of a growing film will also reach the region and the ion-sputtered atoms from a target will crystallize directly in the form of $\alpha_{1}+\alpha_{2}$ before being cooled down by the substrate, resulting in a maximum of $M_{\mathrm{s}}$ being retained in the film. If $T_{\mathrm{s}}$ is relative too low or too high, $T_{\text {sur }}$ will be below or beyond the separation region so that no composition segregation will take place.

In the case of bulk, a $\mathrm{CoCr}$ alloy is solidified from melt and cooled down at such a considerable rate that it does not have enough time for atoms to diffuse when passing through the separation region, thus, the as-cast alloy has only a low value of $M_{\mathrm{s}}$ which comes from its nonsegregated $\alpha$ phase.

Sagoi et al. [18] mentioned the fact that the $M_{\mathrm{s}}$ value of as-cast 26 at $\% \mathrm{Cr}$ alloy was above zero at room temperature and it could not increase, even after annealing at $500^{\circ} \mathrm{C}$ for three months. In the current opinion, it could be the reason for no segregation at $500^{\circ} \mathrm{C}$ because it is just beneath the separation region in the phase diagram.

Several interesting questions will now be discussed: 
1) In every $\mathrm{CoCr}$ phase diagram, the transit region of $\alpha+\beta$ appears very narrow and uncertain, which means that the phase transition of $\alpha \leftrightarrow \beta$ is a congruent composition process without diffusion. On the other hand, both lattices of $\alpha$ and $\beta$ are in a close-packed structure. A strong relation has been found between them, because of three pairs of crystal planes with almost equal spacing which can be seen in table 3 . The values given in table 3 are calculated with lattice constants from the ASTM-file. The co-peaks on the $\mathrm{X}$-ray diffraction patterns of $\mathrm{CoCr}$ ribbons can be seen in fig. 9 also. With a similar situation on the close-packed plane, one phase can be changed into the other by moving some atomic layers along this plane to adjust the packing mode, which is usually finished by running dislocations of $b=a[211] / 6$ for a short step. Here $b$ is the dislocation vector and $a$ the lattice constant of the fcc $\beta$-phase. Therefore, it is inferred that this phase transition process should follow a martensitic process, i.e., a very fast action (in a shearing manner). This view is also confirmed by the fact that an as-ribbon sample is unable to avoid having an $\alpha$-phase occurring in it even though it has undergone such a fast quench from its melt, and its acicular morphology, mixed $\alpha$ and $\beta$ as seen in fig. 7, shows a characteristic of martensite. Furthermore, based on TEM observations, recent work of ref. [31] on $\mathrm{CoCr}$ bulk has also proven the martensitic transformation of $\beta \leftrightarrow \alpha$ with a crystal orientation relation of $\alpha-(001) \beta-(111)$ and $\alpha-[110] \beta-[1 \overline{1} 0]$ which is the same as deduced above. However, the contradictory experimental fact is that the $\beta$-phase in the studied ribbons is not completely transformed into an $\alpha$-phase after an anneal step of $700^{\circ} \mathrm{C}$, even for one lasting $15 \mathrm{~min}$. A possible answer is that a fast phase transition of $\alpha \leftrightarrow \beta$ really happens, but it needs a great deal of dislocations to move. Most of the dislocations will cling to each other in a mass or be pinned until the whole transition is completed. Therefore, the martensitic mode will stop and be replaced by a surface-control growing mode which is slow. Thus the actual process of the transition behaves quickly at first but has a sluggish ending. It is difficult to achieve a full single-phase structure in the ribbon by a short-time heat treatment.

2) The increment in $M_{\mathrm{s}}$ of a ribbon at $1000^{\circ} \mathrm{C}$ has been considered as a result of $\mathrm{Cr}_{2} \mathrm{O}_{3}$ formation. However, X-ray diffraction, as shown in fig. 4(d), also indicates the simultaneous existence of $\mathrm{CoO}$ even with a much higher reflection intensity than that for $\mathrm{Cr}_{2} \mathrm{O}_{3}$. If the amount of $\mathrm{CoO}$ were much more than $\mathrm{Cr}_{2} \mathrm{O}_{3}$, as it seemed, the $\mathrm{Cr}$ content left in the unoxidized part of the ribbon would become relatively denser and produce a lower value of $M_{\mathrm{s}}$, instead of the increment. A possible answer is that, when a $\mathrm{Cr}_{2} \mathrm{O}_{3}$ molecule forms, four $\mathrm{CoO}$ ones should do so as well, in order to keep the original composition (e.g. 20 at\% $\mathrm{Cr}$ ) of the ribbon unchanged, thus $\mathrm{CoO}$ is permitted to be relatively more present than $\mathrm{Cr}_{2} \mathrm{O}_{3}$. In addition, the lattice of $\mathrm{CoO}$ is a $\mathrm{NaCl}$-type one with a high symmetry, while, the lattice of $\mathrm{Cr}_{2} \mathrm{O}_{3}$ is only a common hexagon and its symmetry is much poorer. This makes another contribution to the different reflecting intensities.

3) The existence of the assumed phase-separation region requires some direct evidence. Its shape or position needs more accuracy. Another possibility is that the region really looks like the one in fig. 15, which is different from that in fig. 14. The open lower part means that an alloy within the region of a lower temperature will have practically no separation of $\alpha_{1}+\alpha_{2}$ from $\alpha$, because of a rather slow diffusion. The left boundary of the region is located by part of the line dividing $\alpha$ and $\alpha+\beta$ regions in fig. 1(a), and its right boundary partly by another line dividing $\mathrm{CO}_{3} \mathrm{Cr}+$ $\mathrm{Co}_{2} \mathrm{Cr}$ and $\mathrm{Co}_{2} \mathrm{Cr}$ regions in fig. 1(b). It is interesting to note literature [31] where the authors suc-

Table 3

Pairs of crystal planes with equal spacing

\begin{tabular}{llllll}
\hline$\alpha-(002)$ & $d=2.0350 \AA$ & $\alpha-(110)$ & $d=1.2535 \AA$ & $\alpha-(112)$ & $d=1.0672 \AA$ \\
$\beta-(111)$ & $d=2.0465 \AA$ & $\beta-(220)$ & $d=1.2532 \AA$ & $\beta-(311)$ & $d=1.0687 \AA$ \\
\hline
\end{tabular}




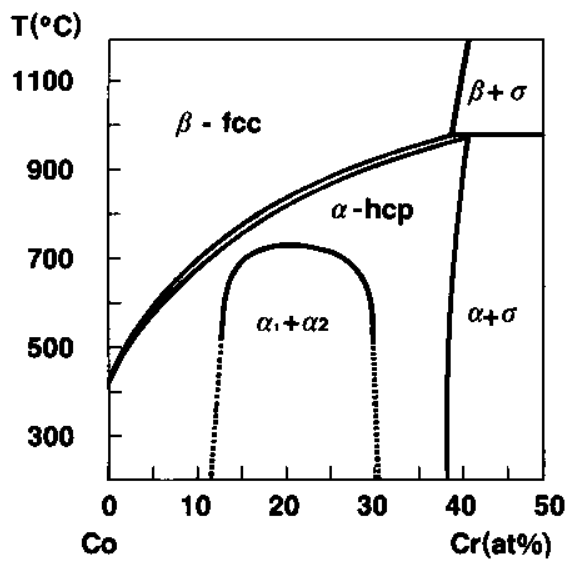

Fig. 15. Another model of the phase separation in $\mathrm{CoCr}$ by $\sigma_{1}+\sigma_{2}$ regions.

ceeded with TEM in distinct observations of magnetic domains in bulk CoCr. Although the samples they used, due to low Cr-content, were out of the so-called phase separation region, the method they used has shed light on future observation of samples with higher $\mathrm{Cr}$-content (e.g. typical $\mathrm{Co}_{80} \mathrm{Cr}_{20}$ ), which is expected to provide clear information on $\mathrm{CoCr}$ phase separation or even to establish its accurate region.

4) Experiments on $H_{\mathrm{c}}$ of quenched 20 at $\mathrm{Cr}$ ribbons have shown no great changes after heating (also above $800^{\circ} \mathrm{C}$ for 27 at $\mathrm{Cr}$ ribbons), no matter how their magnetization varies. However, another fact is that, as shown in fig. 7, acicular morphology always exists inside samples with respect to every heat treatment, and the real sizes of $\alpha$ and $\beta$ grains in this morphology remain unchanged although they can vary the total area of this two-phase mixed structure and also the size of its zone with the arrangement of acicular grains in one direction. Further investigations are necessary.

\section{References}

[1] S. Iwasaki and K. Takemura, IEEE Trans. Magn. MAG-11 (1975) 1173.
[2] Private communication Prof. Ouchi, Tohoku University, Sendai, Japan.

[3] See for example, Proc. PMRC Conf., Tokyo, Japan (1989).

[4] R.M. Bozorth, Ferromagnetism (Van Nostrand, New York, 1951) p. 568.

[5] K. Lewkonja, Z. Anorg. Chem. 59 (1908) 323.

[6] F. Wever and U. Haschimoto, Mitt. Kaiser-Wilhelm-Inst. Eisenforsch., Düsseldorf 11 (1929) 293.

[7] F. Wever and H. Lange, Mitt. Kaiser-Wilhelm-Inst. Eisenforsch., Düsseldorf 12 (1930) 353.

[8] J.W. Weeton, Trans. ASM 44 (1952) 436.

[9] Y. Matsuraga, Kinzoku-no-kenkyu 8 (1931) 549.

[10] A.R. Elsea, A.B. Westerman and G.K. Manning, Trans. AIME 180 (1949) 579.

[11] A.G. Metcalf, Trans. AIME 197 (1953) 357.

[12] A.T. Grigor'ev, E. Yü-p'u and E.M. Sokolovskaya, Russ. J. Inorg. Chem. 6 (1961) 827.

[13] C. Allibert, C. Bernard, N. Valignat and M. Dombre, J. Less-Common Met. 59 (1978) 211.

[14] M. Hansen and K. Auderko Constitution of Binary Alloys, New York (1958) 466.

[15] W.G. Moffatt, The Handbook of Binary Phase Diagrams, (General Electric, 1978).

[16] F. Bolzoni, F. Leccabue, R. Panizzieri and L. Pareti, J. Magn. Magn. Mat. 31-34 (1983) 845.

[17] M. Sagoi, R. Nishikawa and T. Suzuki, IEEE Trans. Magn. MAG-22 (1986) 1335.

[18] M. Sagoi, J. Appl. Phys. 66 (1989) 3173.

[19] J.W. Smits, S.B. Luitjens, F.J.A. den Broeder and A.G. Dirks, J. Magn. Magn. Mat 31-34 (1983) 920.

[20] K. Kobayashi and G. Ishida, J. Appl. Phys. 52 (1981) 2453.

[21] R.D. Fisher, V.S. Au-Yeung and B.B. Sabo, IEEE Trans. Magn. MAG-20 (1984) 806.

[22] M. Hong, R.B. van Dover, J.M. Vandenberg and D.D. Bacon, J. Magn. Magn. Mat. 54-57 (1986) 1585.

[23] Y. Maeda and M. Asahi, J. Appl. Phys. 61 (1987) 1972.

[24] Y. Maeda, PMRC paper and or papers about EPMA analysis.

[25] D.J. Rogers, J.N. Chapman, J.P.C. Bernards and S.B. Luitjens, IEEE Trans. Magn. MAG-25 (1989) 4180.

[26] H. v. Kranenburg, J.C. Lodder, Y. Maeda and L. Toth, IEEE Trans. on Magn. (1990) to be published.

[27] B. Chapman, Glow Discharge Processes (John Wiley, New York, 1990) p. 199.

[28] D. Fowler and J. Rogozik, J. Vac. Sci. Technol. A6 (1988) 928.

[29] I.C. Wright and G.C. Wood, Oxidation of Metals 11 (1977) 163.

[30] Y. Maeda, M. Asahi and M. Seki, Japan. J. Appl. Phys. 25 (1986) L668.

[31] L.H. Chan, G. Thomas and J.S. Gau, J. Magn. Magn. Mat. 79 (1989) 95. 